\title{
Structural Analysis of Gubernaculum Testis in Cryptorchid Patients Submitted To Treatment with Human Chorionic Gonadotrophin
}

\author{
Charbel S. El Zoghbi, Luciano A. Favorito, Waldemar S. Costa, Francisco J. B. Sampaio \\ Urogenital Research Unit, State University of Rio de Janeiro, Rio de Janeiro, RJ, Brazil
}

\begin{abstract}
Objectives: To make a histological and stereological analysis of gubernaculum testis elastic system fibers, collagen and striated muscle cells in patients with cryptorchidism treated with human chorionic gonadotrophin (hCG).

Materials and Methods: Gubernacula tissue samples were obtained from 12 patients with cryptorchidism. Patients' ages ranged from 1 to 3 years (mean 1.8). Of the 12 patients, 6 were treated with hCG. The samples were stained with Masson's trichrome to highlight muscle fibers and collagen, and Weigert's resorcin-fuchsin to highlight the elastic system fibers. The volumetric density of these components was determined by stereological methods.

Results: The volumetric density of collagen was increased in patients treated with hCG, ranging from $85.62 \%$ to $94.48 \%$, while in patients not submitted to hCG treatment the volume density ranged from $52.12 \%$ to $89.46 \%$ ( $\mathrm{p}=0.0052$ ). The volumetric density of the elastic system fibers was higher in patients treated with hCG, ranging from $9.62 \%$ to $19.62 \%$, while patients not submitted to hCG treatment the volume density of elastic system fibers was between $10.38 \%$ and $12.38 \%(\mathrm{p}=$ 0.0030). The volume density of striated muscle fibers in patients treated with hCG ranged from $4.76 \%$ to $39.16 \%$, while and in patients not treated $\mathrm{hCG}$ it ranged from $3.24 \%$ to $11.14 \%(\mathrm{p}=0.0052)$.

Conclusion: Gubernacular components alter significantly when submitted to treatment with hCG. Patients who underwent hCG treatment and had no complete testicular migration had an increase in the concentration of elastic and striated muscle fibers and a decrease in the volumetric density of collagen.
\end{abstract}

Key words: testis; cryptorchidism; human chorionic gonadotrophin; connective tissue; muscle Int Braz. J Urol. 2007; 33: 223-30

\section{INTRODUCTION}

Cryptorchidism is one of the most common developmental defects in human males, with an incidence of 2 to $5 \%$ in full-term newborns (1). The treatment is surgical (2); however, there are reports on several cases of testis migration after hormonal treatment with human chorionic gonadotrophin (hCG) or gonadotrophin releasing factor $(\mathrm{GnRH})(1)$.

The gubernaculum testis seems to be the most important structure involved in testicular migration (3).
The gubernaculum is a mesenchymal structure attached superiorly to the inferior pole of the testis and the epididymal tail (testicular portion) and attached inferiorly in the inguinal canal or scrotum (scrotal portion) $(4,5)$.

Histologically, the gubernaculum is composed of an abundant extracellular matrix that is rich in glycosaminoglycans and mesenchymal cells, such as fibroblasts (6-8). The role of gubernaculum in testicular migration is especially due to its ability to dilate and shorten, thus facilitating the testis course through the inguinal canal (6-8). 
Gubernacular remodeling during fetal period is influenced by direct androgenic stimulation and by the action of the genitofemoral nerve $(9,10)$. The existence of androgenic receptors in the gubernaculum was assessed in experimental studies carried out in rats (11). The existence of these androgenic receptors in human gubernacula is also suggested (10). The role of hCG in the treatment of cryptorchidism is to stimulate testosterone secretion, which induces an increase of androgenic receptors in the gubernaculum $(1,11,12)$.

To our knowledge, there has been no previous study on the structural changes in the gubernaculum testis elastic system fibers, collagen and muscle fibers in patients with cryptorchidism submitted to treatment with hCG, as compared to a control group not submitted to treatment with hCG. Therefore, the aim of this study is to make a histological and stereological analysis of these structures in both groups.

\section{MATERIALS AND METHODS}

We studied 12 gubernacula (Figure-1) from 12 patients with cryptorchidism, ranging in age from 1 to 3 years (mean, 1.8). All patients were submitted to surgical orchidopexy in the period from April 2004 to July 2005. The 12 patients studied were divided according to previous use or not use of hCG.

The hCG treatment doses were delivered according to the World Health Organization recommendations (1), that is, twice a week for a fiveweek period, according to age, children up to 2 years old received intramuscular doses of 250 UI (total of 2500 UI), children older than 2 years received intramuscular doses of $500 \mathrm{UI}$ (total of $5000 \mathrm{UI}$ ). This study was evaluated and approved by the institutional review board at our institution.

Gubernaculum samples were fixed in buffered formalin ( $\mathrm{pH}=7.2$ ), dehydrated in alcoholic solution, clarified in xylol and embedded in paraffin. From each fragment of gubernaculum, we obtained 20 different 5 micrometers thick sections, 5 of these sections were selected and stained with the following histochemical methods. Masson's trichrome to highlight muscle fibers and collagen, and Weigert's resorcin-fuchsin with and without previous oxidation with oxone to highlight the fibers of the elastic system. Metalloproteinase I and III immunohistochemical techniques were used to assess a likelihood of damage to collagen fibers.

Five sections from each sample were selected for the quantitative analysis. We studied 5 microscopic fields chosen at random, totaling 25 test areas studied for each gubernaculum, to a total of 1200 test areas for the complete study.

Imaging for the analysis and quantification of the gubernaculum were obtained in a X400 magnification, under an Olympus optical microscope, coupled to a Sony CCD video camera connected to a Sony KX14-CP1 video monitor. Results for each field were obtained through the quantification assessment method, by superposing an M42 test grid (multipurpose test system) on the video monitor screen (13).

The arithmetic mean of the quantification in 5 fields of each section was determined. Afterwards, we obtained the mean quantification value for the 5 sections studied from each gubernaculum (total of 25

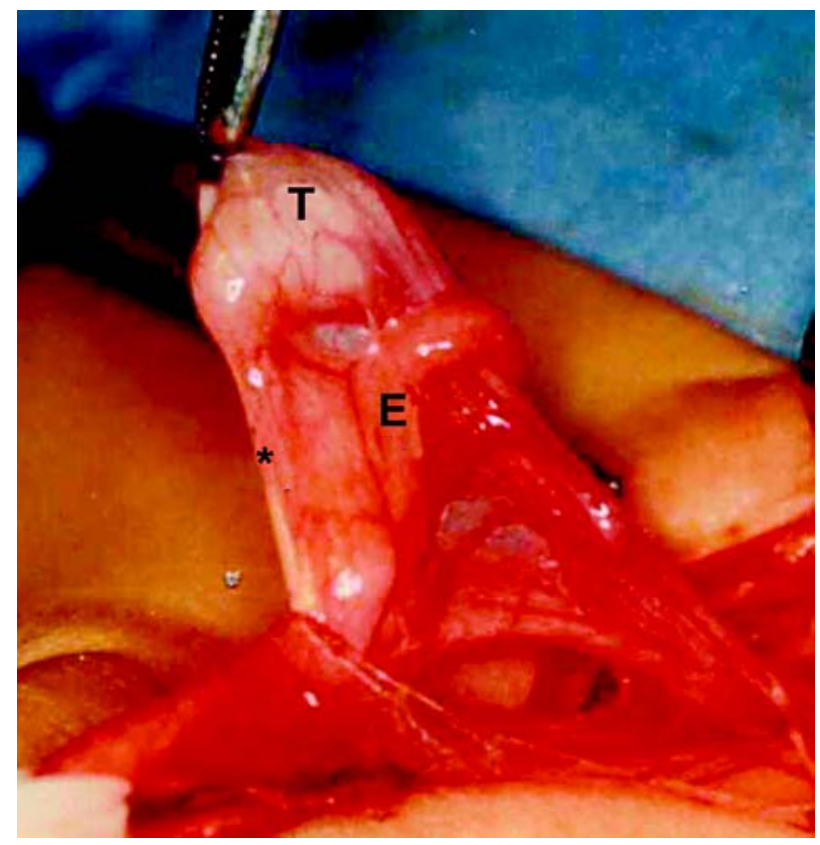

Figure 1 - This figure shows a patient with cryptorchidism during surgery. The testis was in the inguinal canal and we can observe the gubernaculum testis (*) attached to the inferior pole of the testis $(T)$ and the epididymis $(E)$, which presented a disjunction anomaly in this patient. 
test areas). General means of each studied gubernaculum was divided by 42 (number of grid points used in the stereological assessment) and the percent value of fibers per gubernaculum was calculated.

The structures were analyzed and compared through Kolmogorov-Smirnov test. Student's t test, not paired, was used to test if the difference in the means and the standard deviations between the 2 groups was significant (14).

\section{RESULTS}

Patient age, cryptorchid testis position and the mean volumetric density of collagen, striated muscle and elastic system fibers are shown in Table-1 for patients that used hCG and in Table-2 for patients that did not use hCG. In our sample, all patients had unilateral cryptorchidism and their testes were located in the inguinal canal.
The statistical analysis for volumetric density of collagen, striated muscle and elastic system fibers of the studied gubernacula are shown in Figure-2. Of the three elements, independently of hCG use or not, collagen fibers are present in largest amount in the gubernaculum of the studied patients, and the mean concentration of collagen was more than two times the mean concentration of the elastic system fibers and striated muscle fibers.

The volumetric density of collagen was higher in patients submitted to treatment with hCG and ranged from $85.62 \%$ to $94.48 \%$, whereas in patients not treated with hCG the collagen density ranged from $52.12 \%$ to $89.46 \%$ (statistically significant, $\mathrm{p}=0.0052$ ). Figure- 3 shows the histological aspect of collagen distribution in patients submitted and not submitted to hCG treatment previous to surgery. We can observe a lower concentration of collagen in patients submitted to hCG treatment.

Table 1 - Characteristics and results of the volumetric density evaluation (mean) in patients submitted to treatment with human chorionic gonadotrophin.

\begin{tabular}{lccccc}
\hline Age & Side & Testicular Position & $\begin{array}{c}\text { Elastic System } \\
\text { Fibers }\end{array}$ & $\begin{array}{c}\text { Striated Muscle } \\
\text { Fibers }\end{array}$ & Collagen Fibers \\
\hline 1 & right & canalicular & $9.6 \%$ & $4.7 \%$ & $89.4 \%$ \\
1 & left & canalicular & $10.7 \%$ & $8.6 \%$ & $85.1 \%$ \\
2 & right & canalicular & $15.0 \%$ & $28.1 \%$ & $65.6 \%$ \\
2 & left & canalicular & $19.6 \%$ & $39.1 \%$ & $52.1 \%$ \\
2 & right & canalicular & $18.1 \%$ & $36.1 \%$ & $57.6 \%$ \\
3 & left & canalicular & $14.6 \%$ & $23.3 \%$ & $70.0 \%$ \\
\hline
\end{tabular}

Table 2 - Characteristics and results of the volumetric density evaluation (mean) in patients not submitted to treatment with human chorionic gonadotrophin.

\begin{tabular}{lccccc}
\hline Age & Side & Testicular Position & $\begin{array}{c}\text { Elastic System } \\
\text { Fibers }\end{array}$ & $\begin{array}{c}\text { Striated Muscle } \\
\text { Fibers }\end{array}$ & Collagen Fibers \\
\hline 1 & left & canalicular & $12.0 \%$ & $11.1 \%$ & $85.6 \%$ \\
1 & right & canalicular & $12.3 \%$ & $4.2 \%$ & $94.4 \%$ \\
2 & right & canalicular & $10.3 \%$ & $7.2 \%$ & $90.8 \%$ \\
2 & right & canalicular & $11.2 \%$ & $3.2 \%$ & $93.7 \%$ \\
2 & left & canalicular & $12.0 \%$ & $3.7 \%$ & $91.4 \%$ \\
3 & left & canal & $11.6 \%$ & $5.9 \%$ & \\
\hline
\end{tabular}




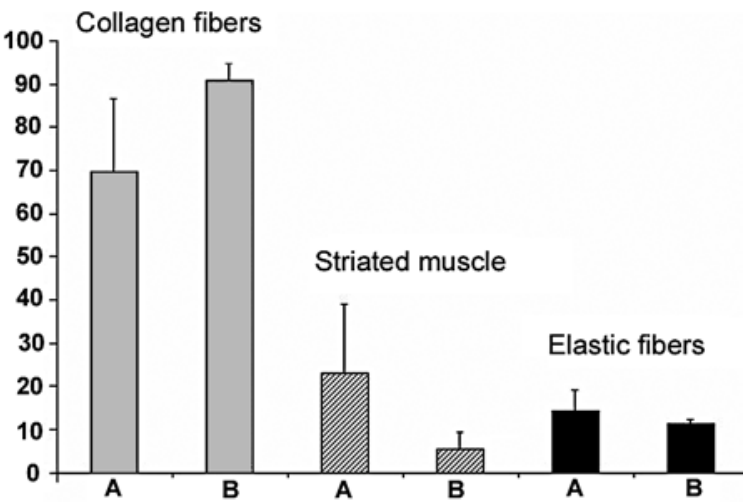

Figure 2 - This figure shows a statistical analysis through a not paired test of the mean values found in the quantification of collagen (grey), striated muscle (hachured) and elastic fibers (black) in patients submitted $(A)$ and not submitted $(B)$ to treatment with human chorionic gonadotrophin.

The volumetric density of elastic system fibers was higher in patients submitted to treatment with hCG and ranged from $9.62 \%$ to $19.62 \%$, whereas in patients not submitted to treatment with hCG the volumetric density of elastic system fibers ranged from $10.38 \%$ to $12.38 \%$ (statistically significant, $\mathrm{p}=0.0030$ ). Figure4 shows the distribution of elastic system fibers in patients submitted and not submitted to hCG treatment previous to surgery. We can observe a high concentration of elastic system fibers in a patient treated with hCG (Figure-4A) when compared to a patient not treated with hCG (Figure-4B).

The volumetric density of striated muscle fibers was higher in patients submitted to treatment with hCG and ranged from $4.76 \%$ to $39.16 \%$, whereas in patients not submitted to treatment with hCG the volumetric density of striated muscle ranged from $3.24 \%$ to $11.14 \%$ (statistically significant, $p=0.0052$ ). Figure-5 shows the histological distribution of striated muscle fibers in patients treated and not treated with hCG.

\section{COMMENTS}

The gubernacular structure undergoes major changes during the human fetal period. The gubernaculum grows in volume during the second trimester of pregnancy and undergoes a decrease in its turgidity and a shortening after the passage of the testicle through the inguinal canal $(7,8,11,15)$. The hormones would have an important role in this reshaping, stimulating the fibroblasts to secrete metalloproteinases, which would act in the modifications of the gubernaculum extracellular matrix $(11,16)$.
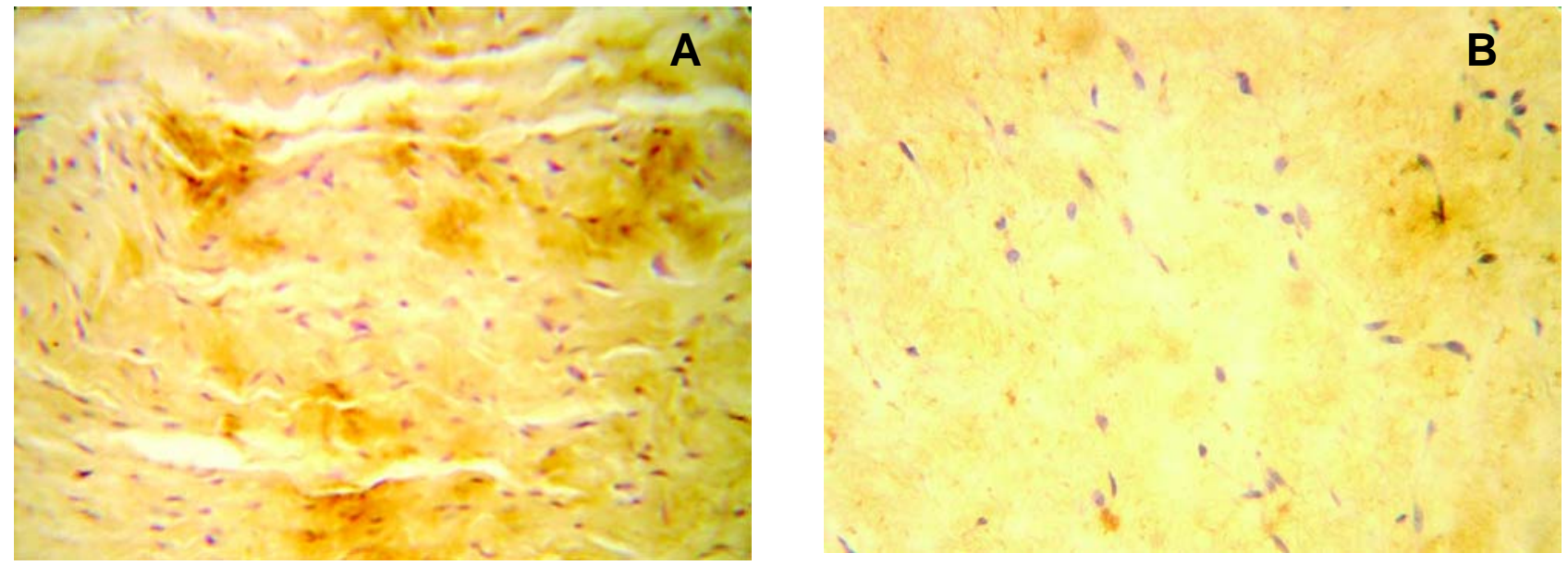

Figure 3 - A) Photomicrography of the gubernaculum from a two-year-old patient submitted to treatment with human chorionic gonadotrophin $(h C G)$. We can observe the collagenase activity in different points of the analyzed field (Metalloproteinases type I, X400). B) Photomicrography of the gubernaculum of a two-year-old patient not submitted to treatment with hCG. We can notice few collagenase activity throughout the analyzed area (Metalloproteinases type I, X400). 

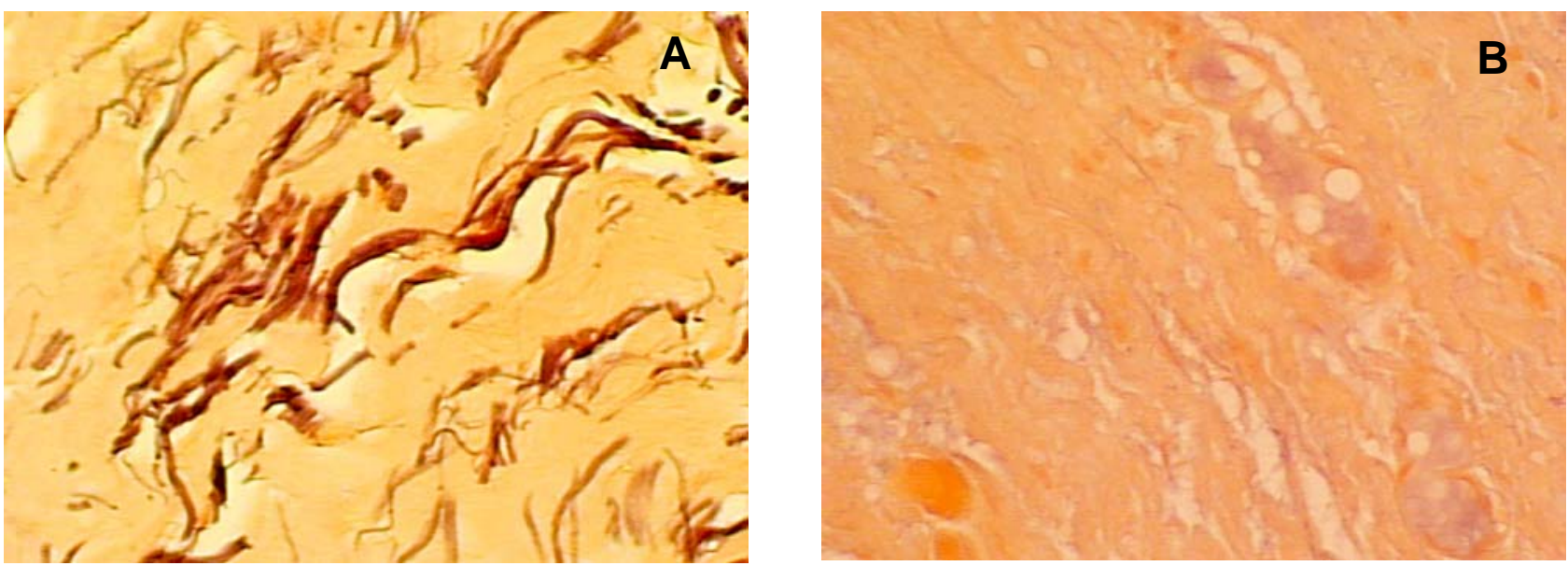

Figure 4-Distribution of elastic system fibers in the gubernaculum testis. A) Photomicrography of the gubernaculum of a one-year-old patient submitted to treatment with human chorionic gonadotrophin ( $h C G)$. Weigert's resorcin-fuchsin, X400. B) Photomicrography of the gubernaculum of a three-year-old patient not submitted to treatment with hCG. We notice small amount of elastic system fibers (Weigert's resorcin-fuchsin, X400).
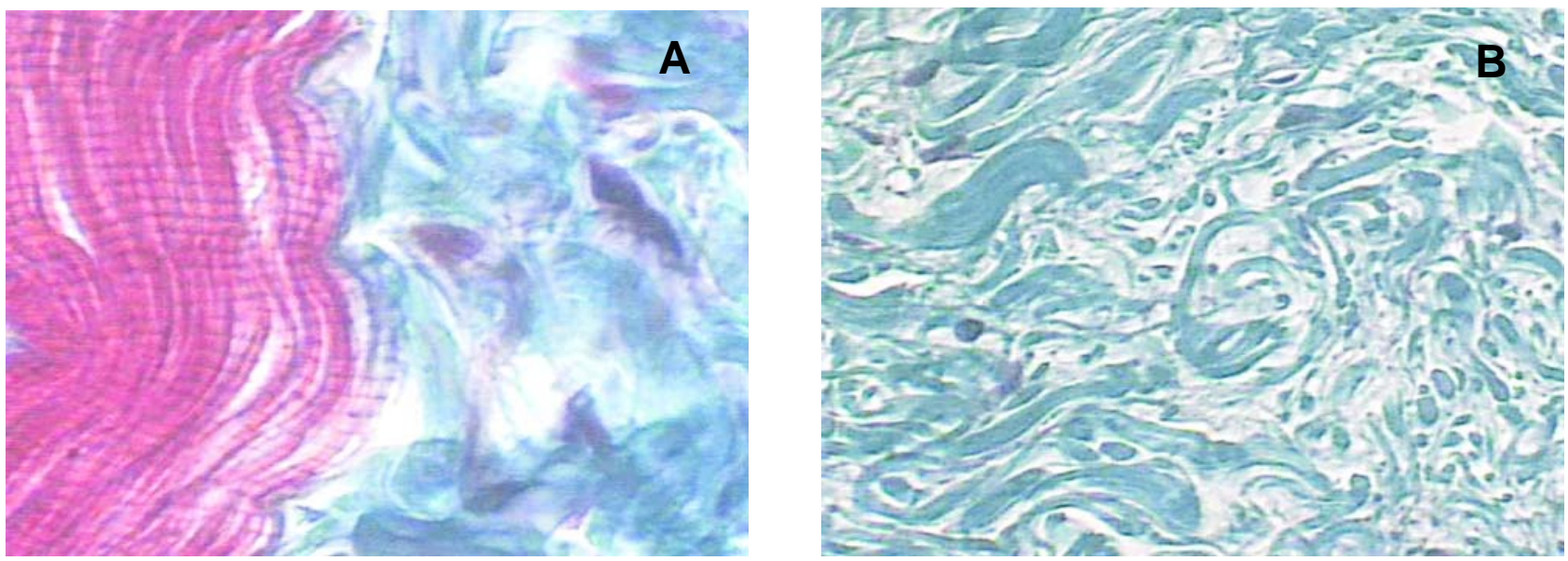

Figure 5-Distribution of striated muscle in the gubernaculum testis. A) Photomicrography of the gubernaculum from a two-year-old patient submitted to treatment with human chorionic gonadotrophin (hCG) showing the typical aspect of striated muscle fibers (Masson's trichrome, X1000). B) Photomicrography of the gubernaculum of a three-year-old patient not submitted to treatment with hCG(Masson's trichrome, X400).

The use of hormones (hCG and GNRH) is the only known clinical treatment for cryptorchidism, with a success rate ranging from $15 \%$ to $50 \%$ (1). The histological changes caused by the use of hCG in the germinative epithelium and in testicular collagen fibers are well known $(17,18)$, however, the structural changes in the gubernaculum, caused by the use of hCG are not described in details.

A hypothesis that could explain the migration process of the testicle after using hCG, would be the increase in the amount of testosterone, inducing the appearance of androgenic receptors on the fibroblasts of the gubernaculum which would degrade the extracellular matrix and would stimulate the contraction of the muscle fibers in the gubernaculum, thus determining its shortening (11). Since the hCG acts through receptors coupled to $G$ proteins, the signals initiated after hCG administration may play a role in these findings. Structures associated with undescended testis reveals evidence of subjecting to 
less sympathetic, but more parasympathetic tonuses. This signaling activates phospholipase $\mathrm{C}$, however, binding of hCG activates adenyl cyclase. Those differences may provide basis for less volume density of collagen and higher volume density of elastic fibers in gubernaculums during testicular migration $(19,20)$. This theory explains the presence of striated muscles in the gubernaculum $(10,11)$. In our study, we have noticed that patients who have undergone the treatment with hCG had a concentration of striated muscle fibers much higher than patients who had not taken the hormone, which may reinforce the theory that the use of hCG induces an increase in the gubernaculum ability to contract.

The only report in the literature that analyzes the elements of the gubernaculum in patients with cryptorchidism submitted to clinical treatment with hCG (21) does not refer to a control group (patients not treated) and shows a lack of glycosaminoglycans and muscle tissue in cryptorchid gubernacula (21).

The elastic system fibers, present in small amounts at the beginning of human fetal period, grow larger in fetuses' gubernaculum older than 25 weeks (8). In fetuses with 28 and 29 weeks of age, whose testicles have already completed their migration (located in the scrotum), the elastic system fibers were present in great quantity, mainly in the distal portion of the gubernaculum (8).

The elastic system fibers are structures that change a lot in the gubernaculum, and are responsible for the shortening of the gubernaculum and its later change into a band of connective tissue (8). The expression of androgenic receptors stimulated by testosterone induces a reshape of the extracellular matrix, so that the gubernaculum gets shorter through the contraction originated in the striated muscle fibers as well as in the increase of elastic system fibers concentration (11). We have noticed, in our study, that the volumetric density of the elastic system fibers in the gubernaculum was much higher in patients with cryptorchid testes who received hCG, which would be another evidence that would support the theory of the expression of androgenic receptors.

During the period of testicular migration, the connective tissue of the gubernaculum undergo an important reshape and becomes, at the end of the migration, a fibrous structure essentially rich in collagen tissue (8). Of the 3 structural elements of the gubernaculum that had been studied here, the collagen was the one that had been present in greater concentration, independently of the use of hCG.

The increase in the volumetric density of collagen, even in patients with cryptorchidism, shows that structural reshape of the gubernaculum extracellular matrix took place, nevertheless, this reshape would not result in complete testicular migration (22). We have noticed in our study that the volumetric density of collagen was much higher in patients who had not taken hCG. These findings may suggest that patients who used the hormone kept a reshape of the gubernaculum connective tissue, causing a decrease in the volumetric density of collagen fibers, possibly indicating an increase in the activity of the metalloproteinases. Patients who were studied here have not shown a complete migration of the cryptorchid testicle, which may indicate a failure of the factors that stimulated the complete reshape, such as, for instance, a deficiency of the androgenic receptors on the gubernaculum.

We concluded that the histological constituents of the gubernaculum undertake a major change when submitted to treatment with hCG. Patients that received hCG and did not experience complete testicle migration, showed an increase in the concentration of elastic and striated muscle fibers and a decrease in the relative concentration of collagen. These changes could be related to the stimulation that testosterone exerts on the androgenic receptors causing the shortening of the gubernaculum.

\section{ACKNOWLEDGMENT}

Research supported by FAPERJ (Rio de Janeiro Foundation for Research Support) and CNPQ (National Council for Scientific and Technological Development), Brazil.

\section{CONFLICT OF INTEREST}

None declared. 


\section{REFERENCES}

1. Gill B, Kogan S: Cryptorchidism. Current concepts. Pediatr Clin North Am. 1997; 44: 1211-27.

2. Cendron M, Huff DS, Keating MA, Snyder HM 3rd, Duckett JW: Anatomical, morphological and volumetric analysis: a review of 759 cases of testicular maldescent. J Urol. 1993; 149: 570-3.

3. Heyns CF, Hutson JM: Historical review of theories on testicular descent. J Urol. 1995; 153: 754-67.

4. Favorito LA, Sampaio FJ, Javaroni V, Cardoso LE, Costa WS: Proximal insertion of gubernaculum testis in normal human fetuses and in boys with cryptorchidism. J Urol. 2000; 164: 792-4.

5. Favorito LA, Klojda CA, Costa WS, Sampaio FJ: Is there a relationship with anomalous insertions of the distal gubernaculum testis and testicular ectopia? Analysis in human fetuses and patients with cryptorchidism. J Urol. 2003; 170: 554-7.

6. Backhouse KM: Embryology of testicular descent and maldescent. Urol Clin North Am. 1982; 9: 315-25.

7. Heyns CF: The gubernaculum during testicular descent in the human fetus. J Anat. 1987; 153: 93112.

8. Costa WS, Sampaio FJ, Favorito LA, Cardoso LE: Testicular migration: remodeling of connective tissue and muscle cells in human gubernaculum testis. J Urol. 2002; 167: 2171-6.

9. Beasley SW, Hutson JM: The role of the gubernaculum in testicular descent. J Urol. 1988; 140: 1191-3.

10. Hosie S, Wessel L, Waag KL: Could testicular descent in humans be promoted by direct androgen stimulation of the gubernaculum testis? Eur J Pediatr Surg. 1999; 9: $37-41$.

11. Vigueras RM, Reyes G, Moreno-Mendoza N, MerchantLarios H: Gubernacular fibroblasts express the androgen receptor during testis descent in cryptorchid rats treated with human chorionic gonadotrophin. Urol Res. 2004; 32: 386-90.

\section{Correspondence address:}

Dr. Luciano Alves Favorito

Urogenital Research Unit - UERJ

Av. 28 de Setembro, 87, Fundos - FCM - Térreo

Rio de Janeiro, RJ, 20551-030, Brazil

Fax: + 5521 2587-6121

E-mail: favorito@uerj.br
12. Elder JS, Isaacs JT, Walsh PC: Androgenic sensitivity of the gubernaculum testis: evidence for hormonal/ mechanical interactions in testicular descent. J Urol. 1982; 127: 170-6.

13. Weibel ER, Kistler GS, Scherle WF: Practical stereological methods for morphometric cytology. J Cell Biol. 1966; 30: 23-38.

14. Sokol RR, Rohlf FJ: Biometry. Third edition. New York, Freeman WH. 1995.

15. Heyns CF, Human HJ, De Klerk DP: Hyperplasia and hypertrophy of the gubernaculum during testicular descent in the fetus. J Urol. 1986; 135: 1043-7.

16. Shono T, Suita S, Kai H, Yamaguchi Y: The effect of a prenatal androgen disruptor, vinclozolin, on gubernacular migration and testicular descent in rats. J Pediatr Surg. 2004; 39: 213-6.

17. Lackgren G, Ploen L: The influence of human chorionic gonadotrophin (hCG) on the morphology of the prepubertal human undescended testis. Int $\mathbf{J}$ Androl. 1984; 7:39-52.

18. Kaleva M, Arsalo A, Louhimo I, Rapola J, Perheentupa J, Henriksen K, et al.: Treatment with human chorionic gonadotrophin for cryptorchidism: clinical and histological effects. Int J Androl. 1996; 19: 293-8.

19. Shenker NS, Huynh J, Farmer PJ, Hutson JM: A new role for androgen in testicular descent: permitting gubernacular cell proliferation in response to the neuropeptide, calcitonin gene-related peptide. J Pediatr Surg. 2006; 41: 407-12.

20. Tomiyama H, Hutson JM: Contractility of rat gubernacula affected by calcitonin gene-related peptide and beta-agonist. J Pediatr Surg. 2005; 40: 683-7.

21. Johansen TE, Blom GP: Histological studies of gubernaculum testis taken during orchiopexies. Scand J Urol Nephrol. 1988; 22: 107-8.

22. Soito I, Sampaio FJ, Cardoso LE: Collagen and glycosaminoglycan composition in gubernacula from human fetuses at different gestational ages, and from cryptorchid children. BJU Int. 2003; 91 Suppl 1: 76.

Accepted after revision: December 04, 2006 


\section{EDITORIAL COMMENT}

The role of gubernaculum in descent is written to be through dilating and shortening. This explanation is very controversial. Since the hCG acts through receptors coupled to $G$ proteins, the signals that initiate after hCG administration may play role in those findings. Structures associated with undescended testis reveals evidence of subjecting to less sympathetic, but more parasympathetic tonuses. This signaling activates phospholipase $\mathrm{C}$, however, binding of hCG activates adenyl cyclase. Those differences may provide basis for less volumetric density of collagen and higher volume density of elastic fibers.

The concepts that formed the basis of the manuscript were very different from my concepts of testicular descent. I think that the gubernaculum, which represents the primitive mesenchymal tissue ceases to exist after giving rise to muscles (1). The structures accepted to represent the postnatal gubernaculum are the remnants of processus vaginalis (2). The remnants of processus vaginalis contain smooth muscle. We have some reports on this issue in the literature (3-6). Since structures in boys with undescended testis reveal evidence of being subjected to more parasympathetic tonus, and hCG activates adenyl cyclase through receptors coupled to $\mathrm{G}$ proteins, those signaling mechanisms may actually provide basis for the findings encountered in this study $(7,8)$.

\section{REFERENCES}

1. Tanyel FC, Talim B, Atilla P, Muftuoglu S, Kale G: Myogenesis within the human gubernaculum: histological and immunohistological evaluation. Eur J Pediatr Surg. 2005, 15: 175-9.

2. Tanyel FC, Talim B, Kale G, Buyukpamukcu N: A reevaluation of the structures accepted to represent the postnatal gubernaculum. Urol Int. 2002; 69: 116-9.

3. Tanyel FC, Dagdeviren A, Muftuoglu S, Gursoy MH, Yoruker S, Buyukpamukçu N: Inguinal hernia revisited through comparative evaluation of peritoneum, processus vaginalis, and sacs obtained from children with hernia, hydrocele and undescended testis. J Pediatr Surg. 1999; 34: 552-5.

4. Tanyel FC, Sara Y, Ertunc M, Onur R, Buyukpamukcu $\mathrm{N}$ : Lack of carbachol response indicates the absence of cholinergic receptors in sacs associated with undescended testis. J Pediatr Surg. 1999; 34: 1339-44.

5. Tanyel FC, Talim B, Kale G, Buyukpamukcu N: Differences in the morphology of the processus vaginalis with sex and underlying disease condition. Pathol Res Pract. 2000; 196: 767-70.

6. Tanyel FC, Muftuoglu S, Dagdeviren A, Kaymaz F, Buyukpamukcu N: Myofibroblasts defined by electron microscopy suggest the dedifferentiation of smooth muscle within the sac walls associated with congenital inguinal hernia. BJU Int. 2001; 87: 251-5.

7. Tanyel FC: The descent of testis and reason for failed descent. Turk J Pediatr. 2004; 46 (suppl.): 7-17.

8. Tanyel FC: Obliteration of processus vaginalis: aberrations in the regulatory mechanism result in an inguinal hernia, hydrocele or undescended testis. Turk J Pediatr. 2004; 46 (suppl.): 18-27.

Dr. Feridun Cahit Tanyel Department of Pediatric Surgery Hacettepe University Faculty of Medicine Ankara, Turkey E-mail: ctanyel@hacettepe.edu.tr 